\title{
Article \\ House Dust Avoidance during Pregnancy and Subsequent Infant Development: The Japan Environment and Children's Study
}

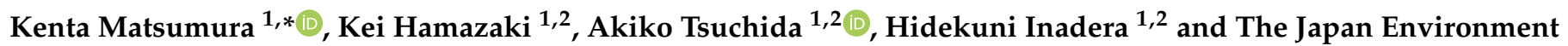 \\ and Children's Study (JECS) Group ${ }^{\dagger}$
}

1 Toyama Regional Center for Japan Environment and Children's Study, University of Toyama, 2630 Sugitani, Toyama 930-0194, Japan; keihama@med.u-toyama.ac.jp (K.H.); aktsuchi@med.u-toyama.ac.jp (A.T.); inadera@med.u-toyama.ac.jp (H.I.)

2 Department of Public Health, Faculty of Medicine, University of Toyama, 2630 Sugitani, Toyama 930-0194, Japan

* Correspondence: kmatsumu@med.u-toyama.ac.jp; Tel.: +81-76-434-7277

+ Membership of the JECS Group is provided in the Acknowledgments. JECS Programme Office, National Institute for Environmental Studies, 16-2 Onogawa, Tsukuba, Ibaraki 305-8506, Japan; jecscore@nies.go.jp.

Citation: Matsumura, K.; Hamazaki, K.; Tsuchida, A.; Inadera, H.; House Dust Avoidance during Pregnancy and Subsequent Infant Development: The Japan Environment and Children's Study. Int. J. Environ. Res. Public Health 2021, 18, 4277. https:// doi.org/10.3390/ijerph18084277

Academic Editor: Paul B. Tchounwou

Received: 9 March 2021

Accepted: 14 April 2021

Published: 17 April 2021

Publisher's Note: MDPI stays neutral with regard to jurisdictional claims in published maps and institutional affiliations.

Copyright: (c) 2021 by the authors. Licensee MDPI, Basel, Switzerland. This article is an open access article distributed under the terms and conditions of the Creative Commons Attribution (CC BY) license (https:// creativecommons.org/licenses/by/ $4.0 /)$.

\begin{abstract}
House dust, well known for causing allergy, contains chemicals that are harmful to fetal neurodevelopment. However, whether countermeasures for house dust allergy, such as frequent use of vacuum cleaners, frequent airing of futons, and the usage of anti-mite covers during pregnancy, are related to subsequent reduced risk of infant developmental delay remains unknown. Therefore, we examined this association by analyzing 81,106 mother-infant pairs who participated in a nationwide birth cohort in Japan. Infant developmental delays at 6 and 12 months postpartum were assessed using the Ages and Stages Questionnaire, Third Edition. A generalized linear model analysis was used to derive adjusted odds ratios (AORs) with the lowest care frequency as reference, while controlling 22 covariates. Our analysis showed that the above-mentioned cleaning measures were overall associated with a reduced risk of developmental delays, both at 6 and 12 months postpartum (AOR varied from 0.73 to 0.95 , median: 0.84 ). Additionally, risks tended to decrease with an increase in the cleaning frequency. In conclusion, a negative dose-response association existed between these measures during pregnancy and infant developmental delay. Our results identify a potential role of frequent vacuum cleaning, airing bedding, and usage of anti-mite bedding covers in promoting intact infant development.
\end{abstract}

Keywords: housekeeping; dust; infant; diagnostic screening programs; psychomotor disorders; communication disorders

\section{Introduction}

House dust has been identified as one of the major causes of allergy. It contains several allergens such as pollen, mites, human and pet skin that mites feed on, and pet hair [1]. Existing countermeasures for house dust allergy, such as asthma and atopic dermatitis, include the frequent usage of a vacuum cleaner, dry-steam cleaning, air purifiers [2], and covering of mattresses and pillows [3], although these anti-house dust treatments are not always effective [4].

Besides allergens, house dust also contains various chemicals such as lead [5], di(2ethylhexyl) phthalate (phthalate ester) [6], polycyclic aromatic hydrocarbons (PAHs) [7], and polybrominated diphenyl ethers [8]. These chemicals are known to interfere with normal infant neurodevelopment [9-11]. For example, fetal exposure to PAHs, measured as mother's exposure to PAHs, is negatively associated with the development of brain white matter, cognition, and behavior in later childhood [12]. Since a series of findings have 
indicated that house dust is one of the principal sources of exposure to these neurotoxicants $[5,7,8,13]$, the above-mentioned countermeasures for allergy may also be negatively associated with the occurrence of infant neurodevelopmental delays. However, the relationship between such countermeasures and infant developmental delay remains unknown.

Therefore, this study examined the prospective relationship between home cleaning measure for house dust avoidance during pregnancy and subsequent development, with a specific focus on frequency of vacuum cleaning, airing of bedding, and anti-mite bedding cover use. We assessed infant development until 1 year of age using a large dataset from the Japan Environment and Children's Study (JECS), a nationwide birth cohort with $>80,000$ records while controlling for possible confounders such as basic characteristics and dwelling environment. We hypothesize that frequent floor and bedding cleaning activities are related to a reduced risk of developmental delay in infants.

\section{Materials and Methods}

\subsection{Study Design and Sample}

The JECS is a nationwide, government-funded birth cohort study investigating the impact of various environmental factors on children's health and development. In the JECS, 103,062 pregnancies were registered between January 2011 and March 2014 via faceto-face recruitment at public agencies across 15 regions, including both rural and urban locations throughout Japan (from the subpolar northern island, Hokkaido, to the southern island, Okinawa). The sample size was determined in advance to maintain adequate statistical power enough to detect rare diseases or conditions such as with $\leq 1 \%$ prevalence. The eligibility criteria for participants (expecting mothers) were as follows: (1) Residence in the study areas at the time of recruitment and expected to reside continuously in Japan for the foreseeable future; (2) expected delivery date between 1 August 2011 and mid2014; (3) ability to comprehend the Japanese language and complete the self-administered questionnaire. Those residing outside the study areas, even if they visited the cooperating health care providers within the study areas, were excluded from the study. Follow-ups were primarily conducted via scheduled in-hospital check-ups until 1 month postpartum and via mailed letters at 6 and 12 months postpartum. Data were acquired using selfadministered questionnaires or transcriptions of medical records recorded by physicians, midwives, nurses, and research coordinators.

The dataset used in this study, jecs-an-20180131, was released in March and updated in December of 2018, and included measurements for the first and second/third trimester, as well as for 0, 1, 6 and 12 months postpartum. Among the 103,062 participants in this dataset, 5647 were excluded due to multiple registrations, 949 due to multiple births, and 3676 following miscarriages or stillbirths. Among the remaining 92,790 pregnancies with singleton live births, 3281 were excluded due to missing information on exposure variables during pregnancy. Another 8403 pregnancies were further excluded due to a lack of responses to the posted Ages and Stages Questionnaire ${ }^{\circledR}$, Third Edition (ASQ-3) [14], both at 6 and 12 months postpartum. Thus, data from 81,106 mother-child pairs were analyzed (Figure 1).

\subsection{Measures}

\subsubsection{Exposure}

A total of four variables measured during the second or third trimester were used as exposure variables: (1) Frequency of cleaning the living room floor with a vacuum cleaner as an average throughout the year (daily, a few times a week, once a week, 1-2 times a month, a few times a year, almost never, or never); (2) frequency of cleaning the futon (Japanese mattress and blanket for bedding) with a vacuum cleaner as an average throughout the year (a few times a week, once a week, 1-2 times a month, a few times a year, almost never, or never); (3) frequency of airing the futon as an average throughout the year (a few times a week, once a week, 1-2 times a month, a few times a year, almost never, or never); (4) usage of anti-mite covers for the futon or bedding after conceiving (yes or no). 


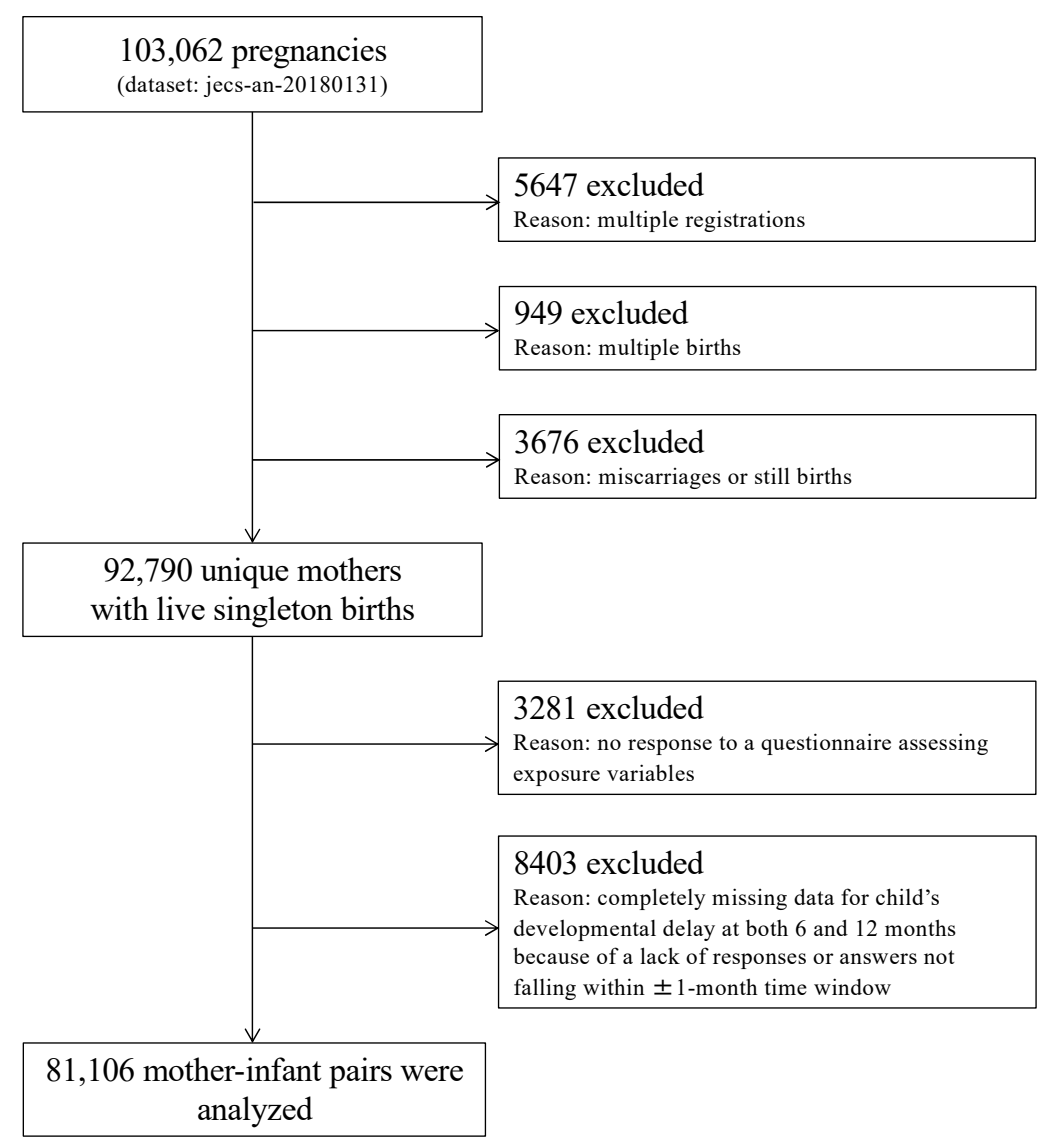

Figure 1. Study flow chart.

Although the average frequency of cleaning the bedroom floor with a vacuum cleaner throughout the year was also measured, this variable was highly associated with the frequency of cleaning the living room floor (Spearman's $\rho($ rho $)=0.79)$ and was therefore not included in our analyses.

All variables (except for usage of anti-mite covers) were recategorized so that each variable consisted of four categories.

\subsubsection{Outcomes}

Children's development at 6 and 12 months after birth was assessed using the ASQ-3, an age-specific, structured, parent-completed child monitoring system [14]. The ASQ-3 is a set of well-validated, globally used questionnaires that is recommended by the United Nations Children's Fund to identify potential delays and help determine which children need further assessment or ongoing monitoring [15]. The Japanese version of the ASQ-3 has also been validated [16] and has already been used in previous studies [17-19]. The ASQ-3 assesses the following five areas of development: (1) Communication: Language skills, such as babbling, vocalizing, listening, and understanding; (2) gross motor: Arm, body, and leg movements to move and play; (3) fine motor: Hand and finger movements; (4) problem solving: Problem-solving skills, learning, and playing with toys; (5) personal-social: Selfhelp skills, solitary social play, and play with toys and others. Each area consists of six developmental items. The parents' responses (yes, sometimes, and not yet) were counted as 10, 5 and 0 points, respectively, and the total score for each area ranged from 0 to 60 points. The screen-positive cases for each area were defined as those with scores on or below the respective threshold values, which were set at -2 standard deviations from the mean (z-score $\leq-2$ ) to yield a sensitivity of $85-92 \%$, a specificity of $78-92 \%$, and a positive predictive value of 32-64\% [14]. Taking early delivery into account, if the parent's 
completion date at 6 and 12 months was not within \pm 1 month from the estimated delivery date, the data were treated as missing values in accordance with the scoring guidelines.

\subsubsection{Covariates}

Unless otherwise specified, covariates were measured during the second or third trimester. We used the following variables as covariates for mothers: maternal age $(<25$, $25-<30,30-<35$ or $\geq 35$ years), pre-pregnancy body mass index asked during the first trimester $\left(<18.5,18.5-<25\right.$ or $\left.\geq 25 \mathrm{~kg} / \mathrm{m}^{2}\right)$, parity (primipara or multipara), history of allergy measured during the first trimester (yes or no), Kessler Psychological Distress Scale (K6) score $(<5,5-12, \geq 13)$ [20-22], smoking status (never, former, or current), alcohol intake (never, former, or current), number of hours spent outdoors $(<1,1-<2,2-<3$ or $\geq 3 \mathrm{~h}$ ), physical activity corresponding to over $10 \mathrm{~min}$ of walking a day (yes or no), quintile of folic acid intake measured using food frequency questionnaire $(\leq 153,154-203,204-257$, 258-337 or $\geq 338 \mu \mathrm{g}$ ) [23,24], marital status assessed during the first trimester (married, single, divorced, or widowed), highest educational level ( $\leq 12,>12-<16$ or $\geq 16$ years), employment status (yes or no), and annual household income $(<4,4-<6$ or $\geq 6$ million Japanese Yen). As covariates for dwelling environment, we used type of residence (wooden detached house, steel-frame detached house, wooden multiple dwelling house/apartment, steel-frame multiple dwelling house/apartment, or other), number of rooms in the house or apartment $(\leq 2,3,4,5$ or $\geq 6)$, living room flooring material (tatami [Japanese straw floor covering], carpet on tatami, wooden flooring/tiles, carpet on wooden flooring/tiles, or other), having a pet (yes or no) [18], usage of air purifiers (yes or no) [17], age of house or apartment building $(<1,1-<3,3-<5,5-<10,10-<20$ or $\geq 20$ years, or unknown), house renovation or interior completion after conception (yes or no), and number of years living in the current place of residence $(<1,1-<3,3-<5,5-<10,10-<20$ or $\geq 20$ years). These covariates comprise the general and socio-economic status and dwelling environment as well as variables that have potential impact on exposure and outcome. Potential mediators were not used as covariates. All continuous variables were categorized in advance in the event that complex relationships should exist. The categorization of these variables was conducted according to usual medical practice or common practice in Japan $[25,26]$ and is shown in Table 1.

Table 1. Characteristics of mothers and dwelling environments.

\begin{tabular}{|c|c|c|c|}
\hline Variable & Category & $n$ & $(\%)$ \\
\hline \multirow[t]{4}{*}{ Age, $y$} & $<25$ & 7971 & $(9.8)$ \\
\hline & $25-<30$ & 23,069 & (28.4) \\
\hline & $30-<35$ & 28,887 & (35.6) \\
\hline & $\geq 35$ & 21,171 & $(26.1)$ \\
\hline \multirow{3}{*}{$\begin{array}{l}\text { Pre-pregnancy body mass } \\
\text { index }{ }^{\mathrm{a}}, \mathrm{kg} / \mathrm{m}^{2}\end{array}$} & $<18.5$ & 13,129 & $(16.2)$ \\
\hline & $18.5-<25$ & 59,722 & (73.7) \\
\hline & $\geq 25$ & 8212 & (10.1) \\
\hline \multirow[t]{2}{*}{ Parity } & Primipara & 34,250 & $(43.3)$ \\
\hline & Multipara & 44,824 & (56.7) \\
\hline \multirow[t]{2}{*}{ History of allergy ${ }^{a}$} & $\mathrm{No}$ & 40,225 & $(49.8)$ \\
\hline & Yes & 40,548 & $(50.2)$ \\
\hline \multirow[t]{3}{*}{$\begin{array}{c}\text { Kessler Psychological Distress } \\
\text { Scale (K6) }\end{array}$} & $<5$ & 58,089 & $(71.7)$ \\
\hline & $5-12$ & 20,482 & $(25.3)$ \\
\hline & $\geq 13$ & 2449 & $(3.0)$ \\
\hline
\end{tabular}


Table 1. Cont.

\begin{tabular}{|c|c|c|c|}
\hline Variable & Category & $n$ & $(\%)$ \\
\hline \multirow[t]{3}{*}{ Smoking status } & Never & 47,394 & $(58.9)$ \\
\hline & Former & 29,877 & $(37.1)$ \\
\hline & Current & 3245 & $(4.0)$ \\
\hline \multirow[t]{3}{*}{ Alcohol intake } & Never & 26,915 & $(33.4)$ \\
\hline & Former & 51,387 & $(63.8)$ \\
\hline & Current & 2212 & $(2.7)$ \\
\hline \multirow{4}{*}{$\begin{array}{l}\text { Number of hours spent } \\
\text { outdoors, hour }\end{array}$} & $<1$ & 14,905 & $(19.1)$ \\
\hline & $1-<2$ & 37,511 & $(48.1)$ \\
\hline & $2-<3$ & 12,306 & (15.8) \\
\hline & $\geq 3$ & 13,338 & $(17.1)$ \\
\hline \multirow[t]{2}{*}{ Physical activity } & No & 18,041 & $(23.0)$ \\
\hline & Yes & 60,535 & (77.0) \\
\hline \multirow[t]{5}{*}{ Quintile of folic acid intake, $\mu \mathrm{g}$} & $\leq 153$ & 15,764 & $(19.4)$ \\
\hline & $154-203$ & 16,285 & (20.1) \\
\hline & $204-257$ & 16,400 & (20.2) \\
\hline & $258-337$ & 16,425 & (20.3) \\
\hline & $\geq 338$ & 16,224 & $(20.0)$ \\
\hline \multirow{3}{*}{ Marital status $^{a}$} & Married & 77,024 & (95.7) \\
\hline & Single & 2803 & $(3.5)$ \\
\hline & Divorced or widowed & 628 & $(0.8)$ \\
\hline \multirow[t]{3}{*}{ Highest education level, y } & $\leq 12$ & 28,351 & $(35.1)$ \\
\hline & $>1 \overline{2}-<16$ & 34,413 & $(42.6)$ \\
\hline & $\geq 16$ & 18,067 & $(22.4)$ \\
\hline \multirow[t]{2}{*}{ Employed } & No & 36,658 & $(45.5)$ \\
\hline & Yes & 43,878 & $(54.5)$ \\
\hline \multirow[t]{3}{*}{$\begin{array}{l}\text { Annual household income, } \\
\text { million yen }\end{array}$} & $<4$ & 29,903 & $(39.5)$ \\
\hline & $4-<6$ & 25,223 & (33.3) \\
\hline & $\geq 6$ & 20,628 & $(27.2)$ \\
\hline \multirow[t]{5}{*}{ Type of residence } & Wooden detached house & 33,280 & $(41.2)$ \\
\hline & Steel-frame detached house & 5108 & $(6.3)$ \\
\hline & $\begin{array}{l}\text { Wooden multiple dwelling } \\
\text { house/apartment }\end{array}$ & 9944 & $(12.3)$ \\
\hline & $\begin{array}{l}\text { Steel-frame multiple dwelling } \\
\text { house/apartment }\end{array}$ & 31,605 & $(39.2)$ \\
\hline & Other & 771 & $(1.0)$ \\
\hline \multirow{5}{*}{$\begin{array}{l}\text { Number of rooms in the } \\
\text { house/apartment }\end{array}$} & $\leq 2$ & 15,212 & $(18.8)$ \\
\hline & 3 & 26,151 & $(32.4)$ \\
\hline & 4 & 15,389 & (19.1) \\
\hline & 5 & 12,093 & $(15.0)$ \\
\hline & $\geq 6$ & 11,883 & $(14.7)$ \\
\hline \multirow[t]{5}{*}{ Living room flooring materials } & $\begin{array}{l}\text { Tatami (Japanese straw floor } \\
\text { covering) }\end{array}$ & 9161 & $(11.3)$ \\
\hline & Carpet on tatami & 7186 & $(8.9)$ \\
\hline & Wooden flooring/tiles & 28,703 & (35.5) \\
\hline & $\begin{array}{l}\text { Carpet on wooden } \\
\text { flooring/tiles }\end{array}$ & 34,390 & $(42.5)$ \\
\hline & Other & 1467 & $(1.8)$ \\
\hline
\end{tabular}


Table 1. Cont.

\begin{tabular}{cccc}
\hline Variable & Category & $n$ & $\mathbf{( \% )}$ \\
\hline Having a pet & No & 62,503 & $(77.2)$ \\
& Yes & 18,451 & $(22.8)$ \\
\hline Usage of air purifiers & No & 39,830 & $(49.2)$ \\
& Yes & 41,152 & $(50.8)$ \\
\hline Age of house/apartment & $<1$ & 4593 & $(5.7)$ \\
building, y & $1-<3$ & 9138 & $(11.3)$ \\
& $3-<5$ & 7701 & $(9.5)$ \\
& $5-<10$ & 12,519 & $(15.5)$ \\
& $10-<20$ & 18,829 & $(23.3)$ \\
& $\geq 20$ & 20,253 & $(25.1)$ \\
Unknown & 7637 & $(9.5)$ \\
\hline House renovation/interior & No & 78,141 & $(96.8)$ \\
finishing after getting pregnant & Yes & 2560 & $(3.2)$ \\
\hline Number of years living in the & $<1$ & 5373 & $(6.8)$ \\
current place of residence & $1-<3$ & 34,072 & $(43.3)$ \\
& $3-<5$ & 17,840 & $(22.7)$ \\
& $5-<10$ & 14,018 & $(17.8)$ \\
& $10-<20$ & 4202 & $(5.3)$ \\
& $\geq 20$ & 3246 & $(4.1)$ \\
\hline
\end{tabular}

Note: Unless otherwise specified, covariates were measured during the second or third trimester. ${ }^{\text {a }}$ measured or asked during the first trimester.

\subsection{Statistical Analysis}

Background differences according to the exposure variables were examined using a chi-squared $\left(\chi^{2}\right)$ test. Given our large sample size and that minor differences could be easily detected, we relied not only on the $p$-value but also on the effect size Cramer's V, the values being independent of the sampling size [27].

Generalized linear models, with logit set as a link function, were used to calculate crude and adjusted odds ratios (ORs) and their 95\% confidence intervals (CIs). Exposure variables were: (1) Frequency of cleaning the living room floor with a vacuum cleaner, (2) frequency of cleaning the futon, (3) frequency of airing the futon, and (4) anti-mite cover use. The lowest category in each variable and non-use of anti-mite covers were set as the reference. Outcome variables were the total number of screen-positive cases (ranging from 0 to 5) each at 6 and 12 months postpartum. For example, if an infant falls in cases of communication, fine motor, and problem solving, the total number equals 3 . In addition, ORs and CIs of screen-positive cases in each developmental area; (a) communication, (b) gross motor, (c) fine motor, (d) problem solving, (e) personal-social (in ASQ-3), were also calculated. The forced entry method was used to include covariates in the multivariable analysis.

SAS 9.4 (SAS Institute Inc., Cary, NC, USA) was used for all statistical analyses.

\subsection{Missing Data}

Of the 81,106 mother-infant pairs included in the study, the missing-data rate was $\leq 1 \%$ for all covariates except for parity $(2.51 \% ; n=2032)$, number of years living in the current place of residence $(2.90 \% ; n=2355)$, physical activity $(3.12 \% ; n=2530)$, average number of hours spent outdoors $(3.78 \% ; n=3046)$, and annual household income $(6.60 \% ; n=5352)$. Each score of the five areas of the ASQ-3 had a $<5.95 \%(\max n=4820)$ missing-data rate at 6 months and $<10.51 \%(\max n=8518)$ at 12 months.

Imputation was conducted using chained equations [28] to obtain 10 imputed data sets. All data were imputed simultaneously, regardless of the measured time points. When 
conducting multiple imputations, auxiliary variables that were likely associated with the analyzed variables were also included so as not to violate the assumption of missing at random. The estimates from each dataset after multiple imputations were combined using the Rubin's rules [29].

\section{Results}

\subsection{Basic Characteristics}

Data from 81,106 mother-child pairs were analyzed. The mothers' mean age during pregnancy was $31.1 \pm 4.99$ (SD) years, mean body mass index before pregnancy was $21.2 \pm 3.24$ (SD), $43.3 \%$ of the mothers were primipara, $35.1 \%$ had less than 12 years of education, $39.5 \%$ had an annual household income of less than four million Japanese yen, $4.0 \%$ were current smokers, and $2.7 \%$ were current alcohol drinkers during pregnancy. The basic characteristics of mothers and dwelling environments during pregnancy are presented in Table 1.

The top three covariates related to each exposure were as follows: not employed (Cramer's V = 0.297), multipara $(\mathrm{V}=0.283)$, and longer hours spent outdoors $(\mathrm{V}=0.085)$ for vacuum cleaning of the living room (Table S1); usage of air purifiers $(\mathrm{V}=0.082)$, multipara $(\mathrm{V}=0.071)$, and lower education level $(\mathrm{V}=0.066)$ for vacuum cleaning of the futon (Table S2); multipara $(\mathrm{V}=0.153)$, not employed $(\mathrm{V}=0.128)$ and longer hours spent outdoors $(\mathrm{V}=0.086)$ for airing the futon (Table S3); usage of air purifiers $(\mathrm{V}=0.073)$, folic acid intake $(\mathrm{V}=0.036)$, and lower age of house or apartment building $(\mathrm{V}=0.029)$ for usage of anti-mite covers (Table S4).

The frequency of each exposure measure is listed in Table 2.

Table 2. Exposure variables with respective correlation matrices.

\begin{tabular}{|c|c|c|c|c|c|c|}
\hline & \multirow{2}{*}{$n$} & \multirow{2}{*}{$(\%)$} & \multicolumn{4}{|c|}{ Matrix of Spearman's $\rho$ (rho) } \\
\hline & & & A & B & $\mathrm{C}$ & D \\
\hline \multicolumn{3}{|c|}{ A. Frequency of cleaning the living room floor with a vacuum cleaner } & - & $0.18^{* * *}$ & $0.25^{* * *}$ & $-0.04^{* * *}$ \\
\hline$\leq 1-2$ times a month & 6795 & $(8.4)$ & & & & \\
\hline Once a week & 25,367 & $(31.3)$ & & & & \\
\hline A few times a week & 35,362 & $(43.6)$ & & & & \\
\hline Everyday & 13,582 & $(16.7)$ & & & & \\
\hline \multicolumn{3}{|c|}{ B. Frequency of cleaning the futon with a vacuum cleaner } & & - & $0.10^{* * *}$ & $-0.10^{* * *}$ \\
\hline Almost never or never & 46,045 & $(56.8)$ & & & & \\
\hline A few times a year & 10,286 & $(12.7)$ & & & & \\
\hline $1-2$ times a month & 13,265 & $(16.4)$ & & & & \\
\hline$\geq$ Once a week & 11,510 & $(14.2)$ & & & & \\
\hline \multicolumn{3}{|l|}{ C. Frequency of airing the "Futon" } & & & - & $0.01 *$ \\
\hline Almost never or never & 9591 & $(11.8)$ & & & & \\
\hline A few times a year & 15,673 & $(19.3)$ & & & & \\
\hline 1-2 times a month & 30,118 & $(37.1)$ & & & & \\
\hline$\geq$ Once a week & 25,724 & $(31.7)$ & & & & \\
\hline \multicolumn{4}{|c|}{ D. Using anti-mite cover for futon or bedding after getting pregnant } & & & - \\
\hline No & 74,757 & $(92.2)$ & & & & \\
\hline Yes & 6349 & $(7.8)$ & & & & \\
\hline
\end{tabular}

Note: All were measured during the second or third trimester. ${ }^{* * *} p<0.001,{ }^{*} p<0.05$.

\subsection{Main Analyses}

All generalized variance inflation factors were below 2.45, and therefore, no multicollinearity was detected among any of the covariates.

The mean and standard deviation of the total numbers of screen-positive cases over the five developmental areas were $0.116 \pm 0.106$ (SD) at 6 months and $0.222 \pm 0.273$ (SD) at 12 months. The numbers, crude, and adjusted ORs, according to the exposure variables, are shown in Figure 2. Adjusted ORs varied from 0.74-0.93 (median value $=0.84$ ) at 6 months 
and $0.73-0.95$ (median value $=0.84$ ) at 12 months. Trend test for adjusted models revealed that all $p$-values for trend were $<0.001$.

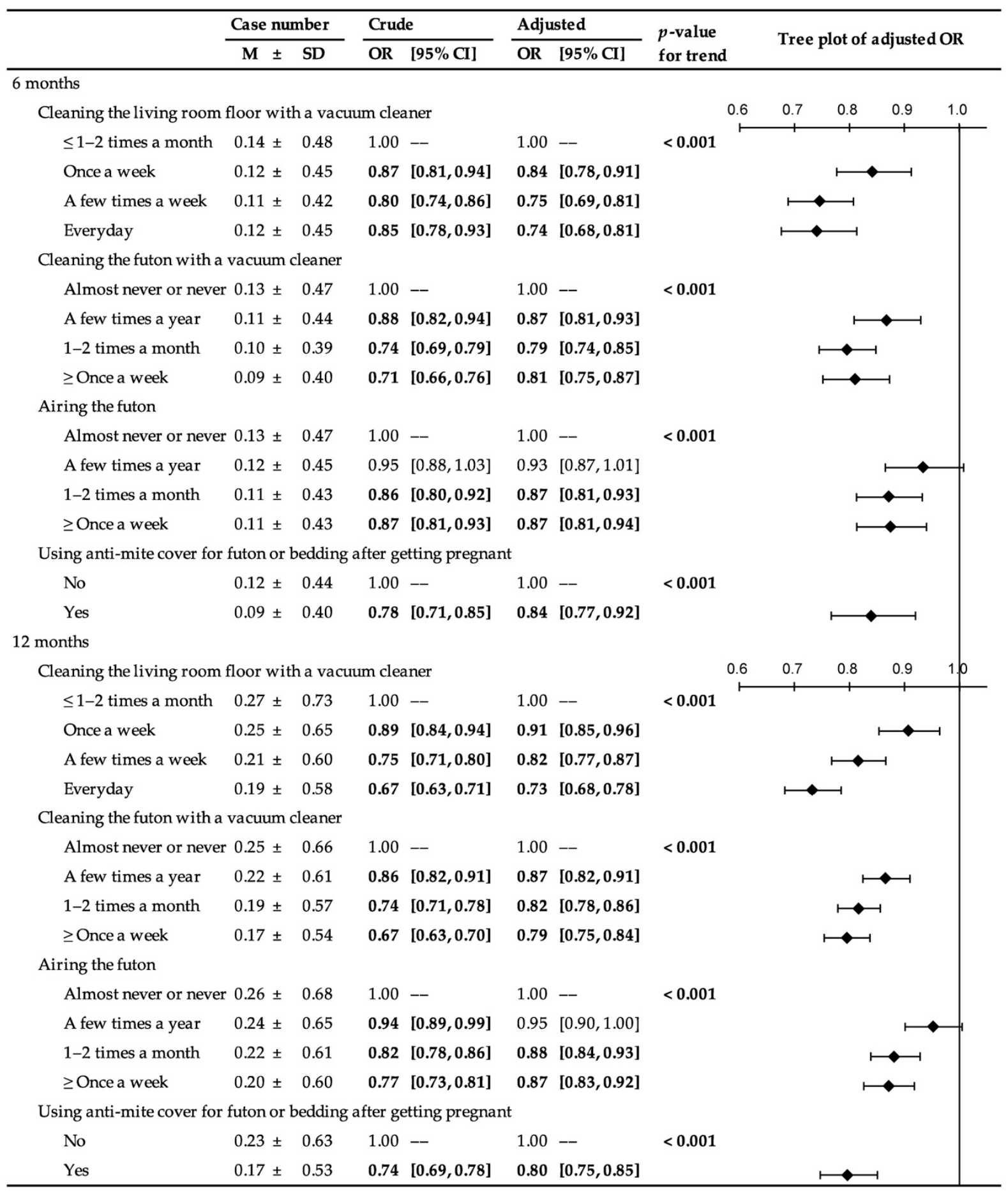

Figure 2. Total number of screen-positive cases over the five developmental areas in the ASQ-3 (case number) and their odds ratios according to the exposure variables (based on imputed data for the 81,106 infants in this study). Boldface indicates statistical significance at the level of 5\%. OR, odds ratio; CI, confidence interval; ASQ-3, Ages and Stages Questionnaire, Third Edition. Crude = crude model. Adjusted = model adjusted for maternal age, body mass index, parity, history of allergy, psychological distress, smoking status, alcohol intake, number of hours spent outdoors, physical activity, folic acid intake, marital status, highest educational level, employment status, annual household income, type of residence, number of rooms in the house or apartment, living room flooring material, having a pet, usage of air purifiers, age of house or apartment building, house renovation or interior completion after becoming pregnant, and number of years living in the current place of residence. $p$-values for trend were calculated for adjusted models. 
The prevalence, as well as crude and adjusted ORs for developmental delay in each developmental area at 6 and 12 months postpartum, according to the exposure variables, are presented in Table S5. Adjusted ORs varied from 0.69-1.04 (median value $=0.83$ ) at 6 months and 0.66-1.01 (median value $=0.86$ ) at 12 months.

\section{Discussion}

To our knowledge, this is the first study to examine the prospective association of home cleaning measures for house dust avoidance during pregnancy, including frequent vacuum cleaning, airing bedding, and usage of anti-mite bedding covers, with subsequent infant development until 1 year of age. To this end, we used a nationwide birth cohort study dataset $(n>80,000)$ while controlling for up to 22 potential confounders with a low level of multicollinearity. Our analyses revealed that adjusted ORs of these cleaning measures for house dust removal, the frequent use of vacuum cleaners, frequent airing of futons, and the usage of anti-mite covers during pregnancy, in screen-positive cases of developmental delay, as per the ASQ-3, were significantly lower compared to the references (which were set to the lowest frequency). This finding remained significant across five areas both at 6 and 12 months postpartum. In addition, the adjusted ORs tended to decrease with an increase in cleaning frequency. Therefore, we found a negative dose-response relationship between house dust avoidance during pregnancy and infant developmental delay.

Fetal exposure to PAHs that are typically found in house dust is associated with decreased birth weight and smaller head circumference [30] as well as reduced brain white matter, cognition, behavior at 8 years [12], and intelligence quotient (IQ) at 5 years of age [9]. Although the detailed mechanisms underlying the relationship between high fetal exposure to PAHs and impaired child neurodevelopment remain unknown, several possible pathways, such as binding to receptors prerequisite for intact fetal growth $[9,30]$ and inflammation and oxidative stress [31], may be involved. Although we observed a negative association between the frequent use of vacuum cleaners, frequent airing of the futon, as well as usage of anti-mite covers and developmental delay until 1 year of age, it remains unclear whether such interventions relate to brain white matter, cognition, behavior, and IQ at later ages. It will be of great importance to examine these aspects as well as the occurrence of developmental delay measured by ASQ-3 at later ages.

It should be noted that conclusions regarding causality cannot be drawn from our findings. Consequently, the observed relationships do not necessarily guarantee that increasing the frequency of cleaning or airing, or introducing anti-mite covers will always prevent infants from developmental delay. In fact, the factors associated with reduced risks for developmental delay through these interventions remain unknown. Thus, further studies conducting randomized controlled trials to address causality, and in-depth studies, such as elucidating factors associated with reduced risk for developmental delay in relation to these interventions and sampling the infant and mother's blood for known household neurotoxins, are warranted.

Frequent cleaning of the floor with a vacuum cleaner and airing of the futon were strongly associated with multipara and unemployment. Mothers with young children are typically required to clean frequently, and being unemployed is virtually equal to being a full-time homemaker in Japan, this allows for daily cleaning and airing of futons. Since working mothers are less frequently at home compared to unemployed mothers, this may reduce the time that can be dedicated to cleaning. Interestingly, a history of maternal allergy was not strongly related to the frequency of these cleaning behaviors, even anti-mite cover use. Thus, the motivation for these living environment cleaning behaviors seems to be based on the natural necessity and capacity in daily life, though the cleaning tasks do not have to be performed by the mother, but by any domestic partner/husband, care taker, home helper, or older child.

The study has two important strengths. First, we included data from an ongoing birth cohort with a large sample of $\geq 80,000$ recruited on a nationwide scale between 2011 and 
2014. Therefore, the sample could be regarded as representative of recent Japanese mothers. Second, although we followed expectant mothers from early pregnancy to 1 year after childbirth, a relatively high response rate was maintained. Consequently, selection bias caused by loss to follow-up was probably small.

The are several limitations to this study. First, we asked only about the frequency of cleaning using vacuum cleaners or airing and did not include other means of removing house dust, such as sweeping or wiping the floor with a broom or a dust cloth. Thus, answering "almost never or never" to the question on the frequency of cleaning with a vacuum cleaner did not necessarily indicate a higher level of house dust. Second, we did not ask about manufacturer names, even though it is known that different vacuum cleaners vary in their cleaning performance, and this may have affected outcomes [32]. Third, we did not have objective data for the decrease in indoor house dust levels after cleaning. While some studies reported that cleaning with vacuum cleaners does result in house dust removal [33,34], others obtained contrasting results [4]. Fourth, although the ASQ-3 is a validated parent-completed questionnaire, its aim is screening, not diagnosis. Thus, the reduced accuracy in assessing signs of developmental delay in this study, as compared with a diagnosis by a professional, should be acknowledged. Finally, while our sample consisted of the JECS nationwide birth cohort, the extent to which our results can be generalized to other living environments such as bed, sleeping mat, and bed-bug protector, cannot be determined. Nevertheless, given that the underlying mechanism of observed reduced risk is actually involved in the removal of many chemicals in house dust, the finding has the potential to be applicable to a wide population.

\section{Conclusions}

Our results derived from 81,106 mother-child pairs indicate a potential role of house dust avoidance, such as frequent vacuum cleaner use, frequent futon airing, and use of anti-mite covers, in promoting intact infant development. This study provides a rationale for conducting randomized controlled trials to address the effect of these measures on inhibiting developmental delay, as well as for in-depth studies elucidating the factors associated with a reduced risk of developmental delay in relation to these home cleaning measures.

Supplementary Materials: The following are available online at https: / www.mdpi.com/article / 10.3390/ijerph18084277/s1, Table S1: Characteristics of the participants with respect to frequency of vacuum cleaning of the living room, Table S2: Characteristics of the participants with respect to frequency of vacuum cleaning of the bedding, Table S3: Characteristics of the participants with respect to the frequency of futon airing, Table S4: Characteristics of the participants with respect to the use of anti-mite bedding covers, Table S5: Prevalence, crude and adjusted odds ratios (ORs), and $95 \%$ confidence intervals (CIs) for the cases of developmental delay in each area assessed using the ASQ-3 according to the exposure variables.

Author Contributions: Conceptualization, K.M. and H.I.; methodology, K.M.; formal analysis, K.M.; data curation, JECS; writing — original draft preparation, K.M.; writing—review and editing, K.H., A.T., H.I. and JECS; funding acquisition, JECS. All authors have read and agreed to the published version of the manuscript.

Funding: The JECS is funded by the Ministry of the Environment, Japan.

Institutional Review Board Statement: The JECS protocol was approved by the Ministry of the Environment's Institutional Review Board for Epidemiological Studies (100910001) and by the ethics committees of all participating institutions. This specific study was also approved by the Ethics Committee, University of Toyama (R2018023) on 12 June 2018.The JECS was conducted in accordance with the Declaration of Helsinki and other nationally valid regulations.

Informed Consent Statement: Informed consent was obtained from all subjects involved in the study. 
Data Availability Statement: The data used to derive our conclusions are unsuitable for public deposition owing to ethical restrictions and the specific legal framework in Japan. Specifically, it is prohibited by the Act on the Protection of Personal Information (Act No. 57 of 30 May 2003, amended 9 September 2015) to publicly deposit data containing personal information. The Ethical Guidelines for Epidemiological Research enforced by the Japan Ministry of Education, Culture, Sports, Science and Technology and the Ministry of Health, Labour and Welfare also restrict the open sharing of epidemiologic data. All inquiries regarding access to the data should be sent to jecs-en@nies.go.jp. The person responsible for handling inquiries sent to this e-mail address is Dr. Shoji F. Nakayama, JECS Program Office, National Institute for Environmental Studies.

Acknowledgments: We are grateful to all of the JECS participants, and to all of the individuals involved in the data collection. Members of the JECS Group as of 2021 are Michihiro Kamijima (principal investigator, Nagoya City University, Nagoya, Japan), Shin Yamazaki (National Institute for Environmental Studies, Tsukuba, Japan), Yukihiro Ohya (National Center for Child Health and Development, Tokyo, Japan), Reiko Kishi (Hokkaido University, Sapporo, Japan), Nobuo Yaegashi (Tohoku University, Sendai, Japan), Koichi Hashimoto (Fukushima Medical University, Fukushima, Japan), Chisato Mori (Chiba University, Chiba, Japan), Shuichi Ito (Yokohama City University, Yokohama, Japan), Zentaro Yamagata (University of Yamanashi, Chuo, Japan), Hidekuni Inadera (University of Toyama, Toyama, Japan), Takeo Nakayama (Kyoto University, Kyoto, Japan), Hiroyasu Iso (Osaka University, Suita, Japan), Masayuki Shima (Hyogo College of Medicine, Nishinomiya, Japan), Youichi Kurozawa (Tottori University, Yonago, Japan), Narufumi Suganuma (Kochi University, Nankoku, Japan), Koichi Kusuhara (University of Occupational and Environmental Health, Kitakyushu, Japan), and Takahiko Katoh (Kumamoto University, Kumamoto, Japan).

Conflicts of Interest: The authors declare no conflict of interest. The funders had no role in the design of the study; in the collection, analyses, or interpretation of data; in the writing of the manuscript, or in the decision to publish the results.

\section{References}

1. Butte, W.; Heinzow, B. Pollutants in house dust as indicators of indoor contamination. Rev. Environ. Contam. Toxicol. 2002, 175, 1-46.

2. Krieger, J.; Jacobs, D.E.; Ashley, P.J.; Baeder, A.; Chew, G.L.; Dearborn, D.; Hynes, H.P.; Miller, J.D.; Morley, R.; Rabito, F.; et al. Housing Interventions and Control of Asthma-Related Indoor Biologic Agents. J. Public Health Manag. Pr. 2010, 16, S11-S20. [CrossRef]

3. Wilson, J.M.; Platts-Mills, T.A. Home Environmental Interventions for House Dust Mite. J. Allergy Clin. Immunol. Pr. 2018, 6, 1-7. [CrossRef] [PubMed]

4. Sercombe, J.K.; Liu-Brennan, D.; Causer, S.M.; Tovey, E.R. The vertical distribution of house dust mite allergen in carpet and the effect of dry vacuum cleaning. Int. J. Hyg. Environ. Health 2007, 210, 43-50. [CrossRef]

5. $\quad$ Lanphear, B.P.; Weitzman, M.; Winter, N.L.; Eberly, S.; Yakir, B.; Tanner, M.; Emond, M.; Matte, T.D. Lead-contaminated house dust and urban children's blood lead levels. Am. J. Public Health 1996, 86, 1416-1421. [CrossRef]

6. Bornehag, C.-G.; Lundgren, B.; Weschler, C.J.; Sigsgaard, T.; Hagerhed-Engman, L.; Sundell, J. Phthalates in Indoor Dust and Their Association with Building Characteristics. Environ. Health Perspect. 2005, 113, 1399-1404. [CrossRef]

7. Maertens, R.M.; Yang, X.; Zhu, J.; Gagne, R.W.; Douglas, G.R.; White, P.A. Mutagenic and Carcinogenic Hazards of Settled House Dust I: Polycyclic Aromatic Hydrocarbon Content and Excess Lifetime Cancer Risk from Preschool Exposure. Environ. Sci. Technol. 2008, 42, 1747-1753. [CrossRef]

8. Wilford, B.H.; Shoeib, M.; Harner, T.; Zhu, J.; Jones, K.C. Polybrominated Diphenyl Ethers in Indoor Dust in Ottawa, Canada: Implications for Sources and Exposure. Environ. Sci. Technol. 2005, 39, 7027-7035. [CrossRef] [PubMed]

9. Perera, F.P.; Li, Z.; Whyatt, R.; Hoepner, L.; Wang, S.; Camann, D.; Rauh, V. Prenatal Airborne Polycyclic Aromatic Hydrocarbon Exposure and Child IQ at Age 5 Years. Pediatrics 2009, 124, e195-e202. [CrossRef]

10. Grandjean, P.; Landrigan, P.J. Neurobehavioural effects of developmental toxicity. Lancet Neurol. 2014, 13, 330-338. [CrossRef]

11. Heyer, D.B.; Meredith, R.M. Environmental toxicology: Sensitive periods of development and neurodevelopmental disorders. NeuroToxicology 2017, 58, 23-41. [CrossRef]

12. Peterson, B.S.; Rauh, V.A.; Bansal, R.; Hao, X.; Toth, Z.; Nati, G.; Walsh, K.; Miller, R.L.; Arias, F.; Semanek, D.; et al. Effects of Prenatal Exposure to Air Pollutants (Polycyclic Aromatic Hydrocarbons) on the Development of Brain White Matter, Cognition, and Behavior in Later Childhood. JAMA Psychiatry 2015, 72, 531-540. [CrossRef]

13. Takagi, M.; Yoshinaga, J. Risk asesment of chemical exposure via house dust ingestion in Japanese children. Indoor Environ. 2009, 12, 103-114. (In Japanese) [CrossRef]

14. Squires, J.; Bricker, D. Ages E Stages Questionnaires (ASQ-3): A Parent-Completed Child-Monitoring System, 3rd ed.; Paul H Brookes Publishing Company: Baltimore, MD, USA, 2009. 
15. Korfmacher, J.; Chawla, N. Toolkit of Recommended Curricula and Assessments for Early Childhood Home Visiting. UNICEF: Geneva, Switzerland; Available online: https://www.unicef.org/eca/sites/unicef.org.eca/files/2017-11/Toolkit_of_ Recommended_Curricula_and_Assessments_for_Home_Visiting_0.pdf (accessed on 9 March 2021).

16. Mezawa, H.; Aoki, S.; Nakayama, S.F.; Nitta, H.; Ikeda, N.; Kato, K.; Tamai, S.; Takekoh, M.; Sanefuji, M.; Ohga, S.; et al. Psychometric profile of the Ages and Stages Questionnaires, Japanese translation. Pediatr. Int. 2019, 61, 1086-1095. [CrossRef]

17. Matsumura, K.; Hamazaki, K.; Tsuchida, A.; Inadera, H. The Japan Environment and Children's Study (JECS) Group The Japan Environment and Children's Study (JECS) Group Prospective Association of Air-Purifier Usage during Pregnancy with Infant Neurodevelopment: A Nationwide Longitudinal Study—Japan Environment and Children's Study (JECS). J. Clin. Med. 2020, 9, 1924. [CrossRef]

18. Minatoya, M.; Araki, A.; Miyashita, C.; Itoh, S.; Kobayashi, S.; Yamazaki, K.; Bamai, Y.A.; Saijyo, Y.; Ito, Y.; Kishi, R.; et al. Cat and Dog Ownership in Early Life and Infant Development: A Prospective Birth Cohort Study of Japan Environment and Children's Study. Int. J. Environ. Res. Public Health 2019, 17, 205. [CrossRef]

19. Hamazaki, K.; Matsumura, K.; Tsuchida, A.; Kasamatsu, H.; Tanaka, T.; Ito, M.; Inadera, H.; Kamijima, M.; Yamazaki, S.; Ohya, Y.; et al. Maternal dietary intake of fish and PUFAs and child neurodevelopment at 6 months and 1 year of age: A nationwide birth cohort-the Japan Environment and Children's Study (JECS). Am. J. Clin. Nutr. 2020, 112, 1295-1303. [CrossRef]

20. Sakurai, K.; Nishi, A.; Kondo, K.; Yanagida, K.; Kawakami, N. Screening performance of K6/K10 and other screening instruments for mood and anxiety disorders in Japan. Psychiatry Clin. Neurosci. 2011, 65, 434-441. [CrossRef]

21. Furukawa, T.A.; Kawakami, N.; Saitoh, M.; Ono, Y.; Nakane, Y.; Nakamura, Y.; Tachimori, H.; Iwata, N.; Uda, H.; Nakane, H.; et al. The performance of the Japanese version of the K6 and K10 in the World Mental Health Survey Japan. Int. J. Methods Psychiatr. Res. 2008, 17, 152-158. [CrossRef]

22. Kessler, R.C.; Andrews, G.; Colpe, L.J.; Hiripi, E.; Mroczek, D.K.; Normand, S.-L.T.; Walters, E.E.; Zaslavsky, A.M. Short screening scales to monitor population prevalences and trends in non-specific psychological distress. Psychol. Med. 2002, 32, 959-976. [CrossRef]

23. Yokoyama, Y.; Takachi, R.; Ishihara, J.; Ishii, Y.; Sasazuki, S.; Sawada, N.; Shinozawa, Y.; Tanaka, J.; Kato, E.; Kitamura, K.; et al. Validity of Short and Long Self-Administered Food Frequency Questionnaires in Ranking Dietary Intake in Middle-Aged and Elderly Japanese in the Japan Public Health Center-Based Prospective Study for the Next Generation (JPHC-NEXT) Protocol Area. J. Epidemiol. 2016, 26, 420-432. [CrossRef] [PubMed]

24. Gao, Y.; Sheng, C.; Xie, R.-H.; Sun, W.; Asztalos, E.; Moddemann, D.; Zwaigenbaum, L.; Walker, M.; Wen, S.W. New Perspective on Impact of Folic Acid Supplementation during Pregnancy on Neurodevelopment/Autism in the Offspring Children-A Systematic Review. PLoS ONE 2016, 11, e0165626. [CrossRef]

25. Hamazaki, K.; Takamori, A.; Tsuchida, A.; Kigawa, M.; Tanaka, T.; Ito, M.; Adachi, Y.; Saito, S.; Origasa, H.; Inadera, H.; et al. Dietary intake of fish and n-3 polyunsaturated fatty acids and risks of perinatal depression: The Japan Environment and Children's Study (JECS). J. Psychiatr. Res. 2018, 98, 9-16. [CrossRef] [PubMed]

26. Matsumura, K.; the Japan Environment and Children's Study (JECS) Group; Hamazaki, K.; Tsuchida, A.; Kasamatsu, H.; Inadera, H. Education level and risk of postpartum depression: Results from the Japan Environment and Children's Study (JECS). BMC Psychiatry 2019, 19, 1-11. [CrossRef] [PubMed]

27. Cohen, J. Statistical Power Analysis for the Behavioral Sciences, 2nd ed.; Routledge: New York, NY, USA, 1988.

28. Van Buuren, S. Multiple imputation of discrete and continuous data by fully conditional specification. Stat. Methods Med. Res. 2007, 16, 219-242. [CrossRef]

29. Rubin, D.B. Multiple Imputation for Nonresponse in Surveys; John Wiley and Sons: New York, NY, USA, 2004.

30. Perera, F.P.; Rauh, V.; Tsai, W.-Y.; Kinney, P.; Camann, D.; Barr, D.; Bernert, T.; Garfinkel, R.; Tu, Y.-H.; Diaz, D.; et al. Effects of transplacental exposure to environmental pollutants on birth outcomes in a multiethnic population. Environ. Health Perspect. 2003, 111, 201-205. [CrossRef]

31. Block, M.L.; Calderón-Garcidueñas, L. Air pollution: Mechanisms of neuroinflammation and CNS disease. Trends Neurosci. 2009, 32, 506-516. [CrossRef]

32. Gore, R.B.; Durrell, B.; Bishop, S.; Curbishley, L.; Woodcock, A.; Custović, A. High-efficiency vacuum cleaners increase personal mite allergen exposure, but only slightly. Allergy 2005, 61, 119-123. [CrossRef]

33. Vojta, P.J.; Randels, S.P.; Stout, J.; Muilenberg, M.; A Burge, H.; Lynn, H.; Mitchell, H.; O'Connor, G.T.; Zeldin, D.C. Effects of physical interventions on house dust mite allergen levels in carpet, bed, and upholstery dust in low-income, urban homes. Environ. Health Perspect. 2001, 109, 815-819. [CrossRef]

34. Yu, C.H.; Yiin, L.-M.; Fan, Z.-H.; Rhoads, G.G. Evaluation of HEPA vacuum cleaning and dry steam cleaning in reducing levels of polycyclic aromatic hydrocarbons and house dust mite allergens in carpets. J. Environ. Monit. 2008, 11, 205-211. [CrossRef] 